(c) American Dairy Science Association, 2006.

\title{
Effects of Dried Dairy Ingredients on Physical and Sensory Properties of Nonfat Yogurt
}

\author{
M. Isleten and Y. Karagul-Yuceer ${ }^{1}$ \\ Canakkale Onsekiz Mart University, Department of Food Engineering, Canakkale, Turkey
}

\begin{abstract}
Physical and sensory attributes are important factors that influence food acceptance and choices. In this study, sensory and texture properties of nonfat yogurts made from reconstituted skim milk powder (SMP) fortified with SMP as a control, whey protein isolate (WPI), yogurt texture improver (TI), and sodium caseinate ( $\mathrm{NaCn}$ ) were investigated over a 12-d storage period. Viscosity and syneresis were measured as physical quality parameters. Descriptive sensory analysis was carried out for each sample to determine the profiles of the products. Consumer acceptance testing ( $\mathrm{n}=143$ consumers) was also conducted to measure the acceptability of yogurts; panelists were asked to rank their preference for the different yogurt samples. Differences among physical and sensory attributes of yogurts were defined. Addition of WPI improved the physical properties of yogurts, resulting in the highest viscosity and the lowest syneresis. On the other hand, yogurt with WPI did not have desirable sensory properties. The descriptive panel indicated that yogurt with WPI had the lowest fermented flavor attribute. In general, yogurts fortified with $\mathrm{NaCn}$ and TI displayed better physical and sensory properties than did control and WPI-fortified yogurts. Consumer testing showed that yogurts with $\mathrm{NaCn}$ and TI were not different from the control with regard to their flavor acceptability. Yogurts fortified with $\mathrm{NaCn}$ and TI were the most preferred samples by Turkish consumers.
\end{abstract}

Key words: yogurt, fortification, sensory, viscosity

\section{INTRODUCTION}

Yogurt is a very popular fermented milk product produced by lactic acid fermentation of milk by addition of a starter culture containing Streptococcus salivarius ssp. thermophilus and Lactobacillus delbrueckii ssp. bulgaricus. It is a very versatile product that suits all palates and meal occasions. Yogurt has many forms including drinkable (liquid) or solid, low fat or fat free, fruity or

Received December 13, 2005.

Accepted March 7, 2006.

${ }^{1}$ Corresponding author: yoncayuceer@comu.edu.tr cereal flavored, and is a healthy and nutritious food (Tamime and Robinson, 2000; McKinley, 2005). Yogurt is the most frequently consumed dairy product in Turkey. Even though we produce some fruit and flavored yogurts, Turkish people mostly prefer to consume, as a meal, plain yogurt with no additional flavoring ingredients. According to a recent study on consumption of animalorigin products by Turkish consumers, the quantity of yogurt consumed was determined to be $9.7 \mathrm{~kg} / \mathrm{mo}$ on average, and mostly consumed by males. In addition, yogurt consumption was high $(9.8 \mathrm{~kg} / \mathrm{mo})$ for consumers older than 30 yr (Akbay, 2006).

Low-fat and fat-free yogurts have gained popularity because of increasing demands of consumers who seek healthy options across product categories. Production of low-fat and nonfat yogurt demands careful control of texture and flavor attributes (Haque and Ji, 2003). One of the most important steps in production of low-fat and fat-free yogurts is to increase total solids content to prevent specific textural defects such as poor gel firmness and surface whey separation (Lucey, 2002). It is common to use skim milk powder (SMP) to fortify yogurt milk, but other dried dairy ingredients such as calcium caseinate, sodium caseinate (NaCn), whey protein concentrate or isolate (WPC or WPI), and other milk protein-based ingredients have gained acceptance as a viable way to increase total solids in fat-free or low-fat yogurts (Tamime and Robinson, 2000). Sodium caseinate is a valuable food ingredient with its high protein content and functional properties of emulsification, water binding, and texture improvement. These functional attributes make this ingredient ideally suited for use in coffee whiteners, baked goods, whipped toppings, infant formulas, and cheese analogs (Ennis and Mulvihill, 2000). Many of the nutrients and bioactive compounds in milk are wasted with whey during cheese making. They are being used in the form of whey powder, demineralized whey, WPC, or WPI (Tamime and Robinson, 2000). Whey protein isolate, the most pure form of whey protein (typically $90 \%$ protein content) also contains little or no fat and lactose and is high in branched-chain amino acids including isoleucine, leucine, and valine. Whey protein isolate is also an excellent source of bioavailable calcium and minerals (Ha and Zemel, 2003). As well as improving 
the textural quality of yogurt including firmness, viscosity, and creaminess, functional ingredients provide health benefits (Hekmat and McMahon, 1997; Drake et al., 2000). From this point of view, ingredients such as WPC, WPI, and NaCn improve nutritional values and biological effects of yogurt on health. These additional properties may affect consumer acceptability and preference (Fox, 2001; Warner et al., 2001).

The impact of different ingredients on the properties of yogurt has been addressed in previous studies. Mistry and Hassan (1992) studied the effects of high milk protein powder (containing $84 \%$ milk protein) on the quality of nonfat yogurts. Powders were added to fluid skim milk to obtain 5.2 to $11.3 \%$ total protein and 11.1 to $15 \%$ total solids. Control yogurts were made from the same skim milk with added NDM of approximately $14 \%$ total solids. Yogurts with more than $5.6 \%$ protein content were too firm and had an astringent taste, according to trained judges. The authors stated that supplementing skim milk up to $5.6 \%$ protein content could produce good quality nonfat yogurts. In another study, some physical properties of set-style, low-fat yogurts fortified with different dried dairy ingredients such as caseinates, coprecipitate (contains all protein fractions of milk), and blended dairy powders up to $4.3 \%$ protein content were studied (Guzman-Gonzalez et al., 2000). The percentage of skimmed milk concentrate replaced with dried dairy products in yogurt milk was between 1.37 and $6.35 \%$. According to their results, yogurt enriched with caseinates had higher viscosity and syneresis index than the others. Sensory properties were not addressed in that study.

Manufacture of yogurt usually involves fortification of milk with dairy ingredients to increase the total solids content. Alternatively, yogurt can be made solely from recombined dried dairy ingredients such as skim milk powder, which is used widely, and other dried dairy ingredients. The aims of this study were to compare the physical and sensory properties of fat-free yogurts made from reconstituted skim milk powder fortified with SMP, WPI, NaCn, or milk protein-based texture improver (TI), to observe the changes in these attributes during storage, and to determine the acceptability of these yogurts by Turkish consumers.

\section{MATERIALS AND METHODS}

\section{Dried Dairy Ingredients and Starter Culture}

Four dried dairy ingredients were used: low-heattreated SMP (Pinar A.S., Izmir, Turkey), and 3 dairy powders provided by Fonterra (Rellingen, Germany): WPI, NaCn, and yogurt TI. According to the manufacturer, yogurt TI is a highly concentrated and functional milk protein-based ingredient, developed as a stabilizer for stirred or set-type yogurt made from skim or whole
Table 1. Composition of dried dairy ingredients ${ }^{1}$

\begin{tabular}{lllll}
\hline & $\begin{array}{l}\text { Skim } \\
\text { milk } \\
\text { powder }\end{array}$ & $\begin{array}{l}\text { Whey } \\
\text { protein } \\
\text { isolate }\end{array}$ & $\begin{array}{l}\text { Texture } \\
\text { improver }\end{array}$ & $\begin{array}{l}\text { Sodium } \\
\text { caseinate }\end{array}$ \\
\hline Protein & 35 & 93.2 & 80.8 & 93 \\
Lactose & 52 & 0.6 & 6.5 & 0.1 \\
Fat & 1 & 0.3 & 2.5 & 0.7 \\
Ash & 8 & 2.1 & 4.3 & 3.6 \\
Moisture & 4 & 5.1 & 5.1 & 4.5 \\
\hline
\end{tabular}

${ }^{1}$ Specifications obtained from the manufacturers. Skim milk powder was from Pinar Sut A.S., Izmir, Turkey; other products were from Fronterra, Rellingen, Germany.

milk. The basic composition of these dried ingredients is shown in Table 1. Commercial freeze-dried yogurt culture (YC 350) was provided by Peyma-Hansen's (Istanbul, Turkey). All dried products were stored at $5^{\circ} \mathrm{C}$ until use.

\section{Yogurt Making}

Yogurt base mix was made by reconstituting SMP in $8 \mathrm{~L}$ of deionized water up to $12 \%$ total solids content. The mix was divided into 4 stainless steel containers (2 L each). To reach $13 \%$ nonfat milk solids, SMP (control), WPI, TI, and $\mathrm{NaCn}$ were added at $1 \%$ (wt/wt) and each mix was mixed thoroughly with a hand blender to obtain a homogeneous yogurt mix.

Containers were placed in a water bath and heated to $90^{\circ} \mathrm{C}$ for $15 \mathrm{~min}$. Mixes were cooled in an ice water bath to the inoculation temperature of $45^{\circ} \mathrm{C}$. Commercial yogurt culture containing $S$. salivarius ssp. thermophilus and L. delbrueckii ssp. bulgaricus was added at a concentration recommended by the manufacturer. The inoculated milks were poured into 200 -g plastic cups with lids and incubated at $45^{\circ} \mathrm{C}$. Incubation was ended when the samples reached $\mathrm{pH}$ 4.7. The fermentation times of all 4 types of yogurt were approximately $4 \mathrm{~h}$. Using different dried dairy ingredients at the $1 \%$ level did not change fermentation rate. After incubation, yogurts were immediately cooled in an ice water bath and stored at $5^{\circ} \mathrm{C}$ for $12 \mathrm{~d}$. Yogurt productions were duplicated.

\section{Physical Properties}

Viscosity. Yogurts were mixed with a hand blender at low speed for $15 \mathrm{~s}$. Viscosities of yogurts were measured at $20^{\circ} \mathrm{C}$ with a Brookfield viscometer (model DV II+ Pro and Rheocalc software; Brookfield Engineering Laboratories, Inc., Middleboro, MA) after 1, 6, and $12 \mathrm{~d}$ of storage. The spindle used (LV-SC4-34 spindle at 4 rpm) was selected based on the torque measurement between 10 and $100 \%$, as suggested by the manufac- 
Table 2. Sensory language for descriptive sensory evaluation of yogurts

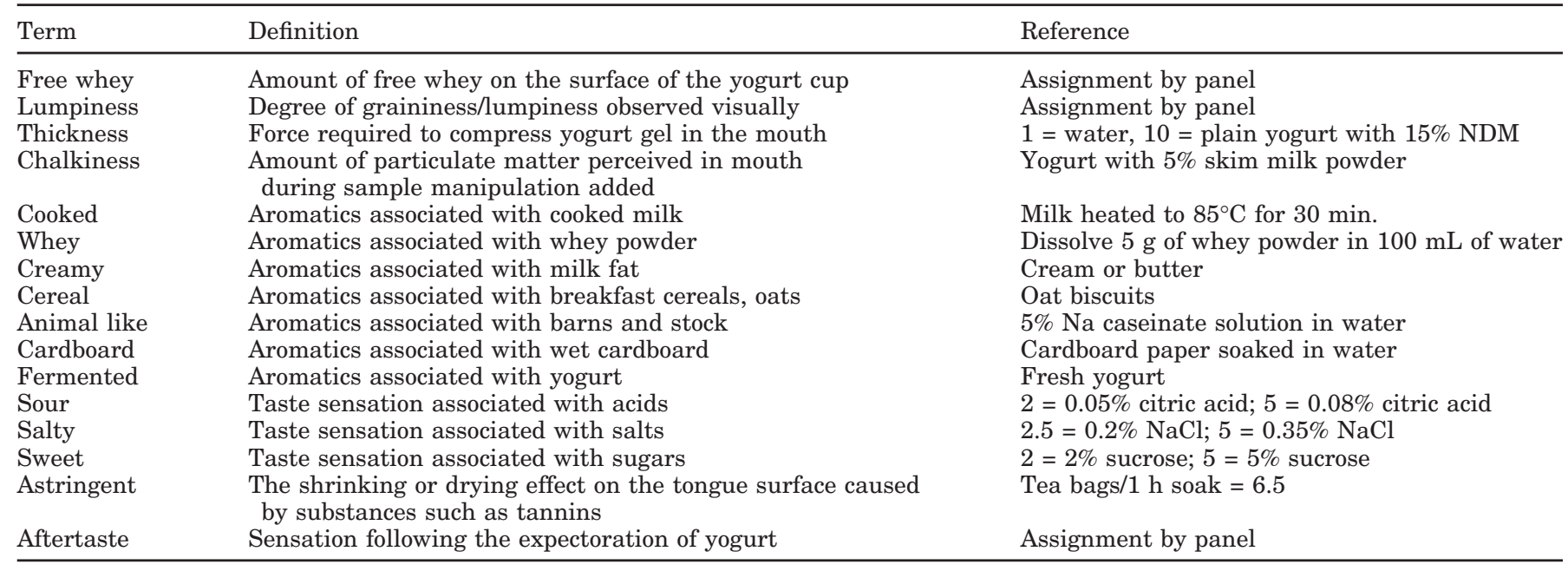

turer. The first result was recorded after a 60 -s rotation of the spindle and the second result was recorded after $70 \mathrm{~s}$ of rotation. Viscosity measurements were duplicated for each yogurt sample.

Syneresis. The syneresis of set yogurts was measured according to Tamime et al. (1996) with a minor modification. The method was based on spontaneous movement of whey out of the gel under the force of gravity. The quantity of whey expelled from a 25-g yogurt sample was expressed as milliliters of drained whey.

\section{Sensory Evaluation}

Descriptive Sensory Evaluation. Eight panelists were selected on the basis of their willingness to participate and previous experience and knowledge on sensory evaluation of dairy and dairy-associated products. Panelists were university staff; 6 were female and 2 were male and ages ranged from 24 to $37 \mathrm{yr}$. Descriptive sensory analysis was conducted on yogurts using the Spectrum procedure described by Meilgaard et al. (1999).

During training, panelists were asked to identify and define visual, texture, and flavor attributes for yogurts. For each training session, all 4 types of samples were presented to panelists to aid identification of terms and references. Visual (free whey), texture (thickness, chalkiness, lumpiness), and flavor (cooked, whey, creamy, cereal, animal-like, cardboard, fermented, sour, salty, sweet, astringent, and aftertaste) attributes were determined. Definitions and references used for each attribute were shown in Table 2. Each attribute was quantified using the Spectrum universal intensity scale from 0 to 15 , where $0=$ not detected and $15=$ extremely strong. Panelists were trained to use the scales using universal references described by Meilgaard et al. (1999). Panelists were already familiar with the scale and some references from previous sensory analysis. Panelists received approximately $30 \mathrm{~h}$ of training focused on yogurt.

All samples were removed from the refrigerator $1 \mathrm{~h}$ before the beginning of every evaluation session. Serving temperature range for samples was 10 to $12^{\circ} \mathrm{C}$. Each yogurt was presented in a 200 -g plastic cup fitted with lid and labeled with a 3-digit code. Order of presentation of samples was randomized. Panelists evaluated each yogurt in duplicate (8 samples per tasting session). Water and expectoration cups were also presented to each panelist to rinse their mouths between samples. Evaluation was divided into 3 sections: visual, texture, and flavor evaluations. For visual attributes, the surface of each yogurt was examined in terms of free whey. After that, texture and flavor evaluations were conducted.

Consumer Acceptance Test. Consumer acceptance testing was conducted on yogurts with participation of university stuff and students $(n=143)$. Yogurts were evaluated $5 \mathrm{~d}$ after manufacture. They were served in 40-mL plastic cups and fitted with lids. Cups were labeled with 3-digit random codes. Each yogurt sample was evaluated for appearance, texture, and flavor on a 9-point hedonic scale anchored on the left with "dislike extremely" and on the right with "like extremely". Consumers were also asked to rank samples according to their acceptance.

\section{Statistical Analyses}

The data were analyzed with Minitab for Windows (version 14.0, Minitab Inc., State College, PA). Analysis of variance was performed on each attribute and data were analyzed for treatment effects, storage effects, and treatment by storage interactions. When significant 
Table 3. Viscosity of yogurts made with added dried dairy ingredients

\begin{tabular}{|c|c|c|c|c|}
\hline & \multicolumn{4}{|c|}{ Dried dairy ingredient } \\
\hline & $\begin{array}{l}\text { Skim milk } \\
\text { powder } \\
\text { (control) }\end{array}$ & $\begin{array}{l}\text { Whey } \\
\text { protein } \\
\text { isolate }\end{array}$ & $\begin{array}{l}\text { Texture } \\
\text { improver }\end{array}$ & $\begin{array}{l}\text { Sodium } \\
\text { caseinate }\end{array}$ \\
\hline $\operatorname{Viscosity}^{1}(\mathrm{cP})$ & $5,243^{\mathrm{c}}$ & $11,069^{\mathrm{a}}$ & $7,363^{\mathrm{b}}$ & $7,120^{\mathrm{b}}$ \\
\hline Treatment $\times$ time $^{2}$ & No & No & No & \\
\hline
\end{tabular}

${ }^{\mathrm{a}-\mathrm{c}}$ Means within a row without a common superscript $\operatorname{differ}(P<$ $0.01)$

${ }^{1}$ Viscosity values are the averages of $\mathrm{d} 1$ to 12 .

${ }^{2}$ Treatment by time interaction.

treatment, time, or interaction effects were observed, Duncan's posthoc test was used for multiple comparisons. Consumer ranking test results were analyzed by nonparametric method (Friedman test). The Dunn test was used for multiple comparisons (Sheskin, 2000).

\section{RESULTS AND DISCUSSION}

\section{Physical Measurements}

Treatment by time interactions were not significant for viscosity measurements $(P>0.05)$ (Table 3$)$. However, there was a significant difference among the yogurts fortified with different ingredients $(P<0.01)$. Yogurts fortified with WPI had the highest viscosity value, whereas the control yogurt had the lowest viscosity. Remeuf et al. (2003) stated that when milk was enriched with WPC (34 to $80 \% \mathrm{wt} / \mathrm{wt}$ protein), heating led to a high level of cross-linking within the gel network, which increased yogurt viscosity and water-holding capacity. Guzman-Gonzales et al. (2000) observed that yogurts containing caseinate showed higher viscosity than those made with blended dairy powders and coprecipitate. Our findings showed that yogurts with $\mathrm{NaCn}$ displayed higher viscosity than control yogurts. In addition, viscosity of yogurts changed over $12 \mathrm{~d}$ of storage $(P<0.01)$. There was no significant difference between yogurts in terms of viscosity on $d 1$ and 6 . The values were 7,136 and $7,505 \mathrm{cP}$ respectively. However, viscosity was higher $(8,456 \mathrm{cP})$ on $\mathrm{d} 12$ than on other days. Throughout storage, protein rearrangement was continuing, and more protein-protein contacts were being established, leading to increasing viscosity during storage (Abu-Jdayil and Mohameed, 2002).

Syneresis is an important defect in yogurt (Lucey, 2002). There was a significant interaction between treatment and storage for syneresis measurements $(P<0.05)$. Figure 1 shows the changes in syneresis over $12 \mathrm{~d}$ of storage. Yogurts fortified with WPI had the lowest level of syneresis. On the other hand, control yogurts consistently displayed higher syneresis compared with other

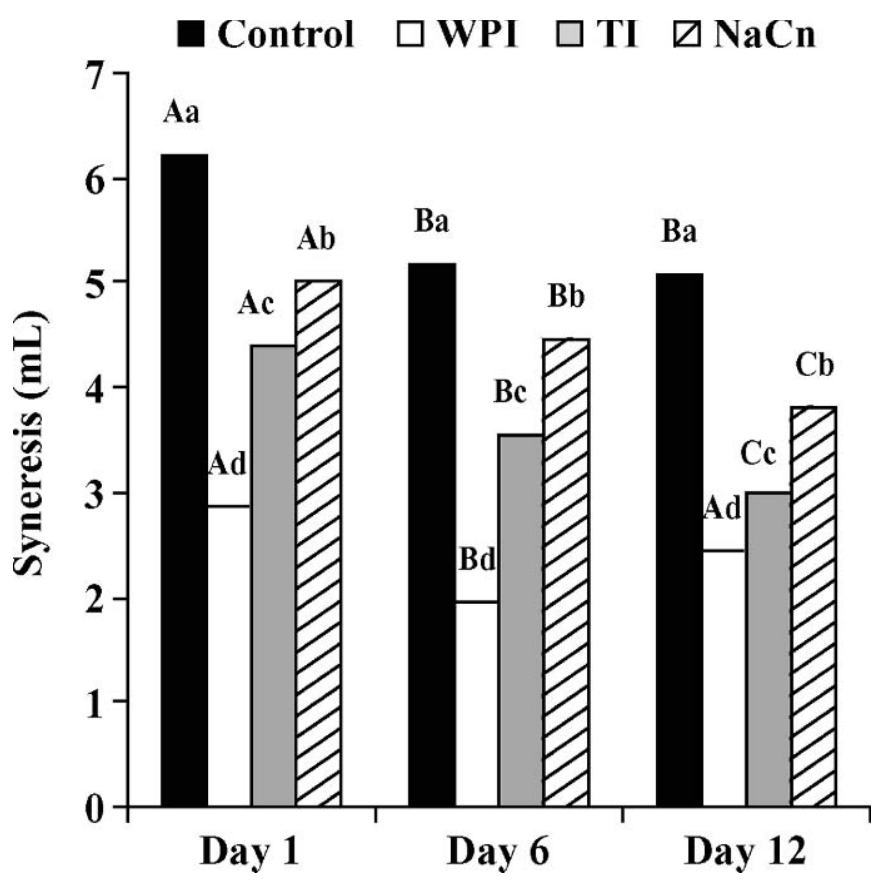

Figure 1. Syneresis ( $\mathrm{mL}$ of whey expelled from a 25-g yogurt sample) of yogurts over $12 \mathrm{~d}$ of storage ${ }^{\mathrm{a}-\mathrm{d}}$ Bars within the same day not sharing a common lowercase letter are different $(P<0.05)$; ${ }^{\mathrm{A}-\mathrm{C}}$ Bars not sharing a common uppercase letter are different for storage period $(P<0.05)$.

yogurts $(P<0.05)$. Syneresis of all yogurts decreased during storage. Other studies have reported that as the casein to whey protein ratio decreases, the network becomes finer, cross links become denser, and the pores smaller, leading to decreasing amounts of syneresis $(\mathrm{Pu}-$ vanenthiran et al., 2002; Amatayakul et al., 2006). Modler et al. (1983) studied 18 skim milk yogurts prepared from combinations of 6 protein types (3 caseinand 3 whey-based products) and 3 protein concentrations $(0.05,1.0$, and $1.5 \%$ added protein). They stated that syneresis decreased with increasing protein concentration and that yogurts fortified with $1.5 \%$ caseinate had significantly less syneresis than the remaining 17 treatments. Whey proteins contain intramolecular disulfide bonds that stabilize their structure. $\beta$-Lactoglobulin contains a sulfhydryl group that becomes active upon denaturation of protein by heat and can subsequently form sulfhydryl-disulfide interactions with itself and other proteins. With these properties, whey proteins affect the structure and rheological properties of coagulated milk gels including yogurt and cheese (Fox, 2001).

\section{Sensory Evaluations}

Visual and Texture Attributes. A significant interaction between time and treatment was observed for free 
Table 4. Sensory attributes of yogurt over $12 \mathrm{~d}$ of storage ${ }^{1}$

\begin{tabular}{lllll}
\hline & \multicolumn{4}{c}{ Yogurt $^{2}$} \\
\cline { 2 - 5 } Attribute & Control & WPI & TI & NaCn \\
\hline Day 1 & & & & \\
Free whey & $2.0^{\mathrm{Ba}}$ & $1.2^{\mathrm{Ab}}$ & $0.5^{\mathrm{Ab}}$ & $0.5^{\mathrm{Ab}}$ \\
Thickness & $5.2^{\mathrm{Cc}}$ & $6.8^{\mathrm{Ba}}$ & $6.7^{\mathrm{Cab}}$ & $6.0^{\mathrm{Cbc}}$ \\
Day 6 & & & & \\
Free whey & $4.00^{\mathrm{Aa}}$ & $1.3^{\mathrm{Ab}}$ & $0.7^{\mathrm{Abc}}$ & $0.5^{\mathrm{Ac}}$ \\
Thickness & $9.5^{\mathrm{Aa}}$ & $8.9^{\mathrm{Aa}}$ & $9.5^{\mathrm{Aa}}$ & $9.5^{\mathrm{Aa}}$ \\
Day 12 & & & & \\
Free whey & $0.8^{\mathrm{Ca}}$ & $0.7^{\mathrm{Aa}}$ & $0.6^{\mathrm{Aa}}$ & $0.4^{\mathrm{Aa}}$ \\
Thickness & $8.6^{\mathrm{Ba}}$ & $8.5^{\mathrm{Aa}}$ & $7.9^{\mathrm{Ba}}$ & $7.9^{\mathrm{Ba}}$ \\
\hline
\end{tabular}

${ }^{\mathrm{a}-\mathrm{c}}$ Means in the same row followed by different lowercase letters represent significant differences $(P<0.01)$.

${ }^{\mathrm{A}-\mathrm{C}}$ Means in the same column followed by different uppercase letters represent significant differences $(P<0.01)$.

${ }^{1}$ Attributes were scored on a 15 -point universal Spectrum intensity scale where $0=$ absence of the attribute and $15=$ extremely high intensity of the attribute (Meilgaard et al., 1999).

${ }^{2}$ Yogurts were fortified with skim milk powder (control), whey protein isolate (WPI), texture improver (TI), or sodium caseinate (NaCn).

whey $(P<0.05$; Table 4$)$. The control yogurt had more free whey than others on $d 1$ and 6 . Physical measurements showed that control yogurt had more syneresis than others (Figure 1). No significant differences were observed among the other 3 yogurts on $\mathrm{d} 1$ and 12 (Table 4). Gonzalez-Martinez et al. (2002) studied the influence of substituting milk powder with whey powder in nonfat yogurts. They prepared yogurt milk from reconstituted skim milk powder with $3 \%$ protein content. It was fortified by adding SMP or mixtures containing both milk powder and whey powder, to adjust the total protein content to $4.2 \%$ in the final yogurt. According to sensory assessment, free whey was lower in yogurts containing 3.64 and $5.2 \%$ whey powder than in the controls (treatment without whey powder).

There was no significant interaction between time and treatment of lumpiness $(P>0.05)$. There was a significant difference in lumpiness among yogurt samples $(P<$ 0.01 ). Lumpiness was the highest in WPI-fortified yogurt (6.5) and the lowest in control (2.4) and $\mathrm{NaCn}$-fortified (2.7) yogurts. Lumpiness refers to the presence of large protein aggregates in yogurt that can range in size from 1 to $5 \mathrm{~mm}$. The effect of storage was significant on lumpiness scores $(P<0.01)$. The lowest lumpiness score (3.0) was observed on d 12. Substituting WPC for SMP to elevate the total solids content of yogurt mixes increases lumpy or granular defects (Lucey and Singh, 1998). In contrast to our findings, Gonzalez-Martinez et al. (2002) stated that yogurts fortified with whey powder showed better flow properties (more homogeneous fluid without lumps) and softer gel textures than yogurts prepared with SMP. This might be the reason for compositional differences between whey powder and WPI.
There was a significant interaction between time and treatment regarding the thickness attribute $(P<0.05$; Table 4). Thickness intensities were higher in yogurts with WPI and TI compared with control on d 1 . However, no significant differences were observed among the yogurts in terms of thickness scores on d 6 and 12; thickness of yogurts increased with time. Drake and coworkers (2000) evaluated the thickness of yogurts fortified with soy protein over 4 wk of storage. They stated that using 1 and $2.5 \%$ soy protein concentrate in yogurts did not result in significant difference in thickness scores compared with controls. Thickness intensities in yogurts with 5\% added soy protein were higher compared with controls. Also, they showed that storage time did not affect texture properties of soy-fortified yogurts evaluated in that study. Using different protein sources may result in differences among sensory textural properties of yogurts.

Sensory analysis showed that lumpiness intensities of yogurts with WPI were higher than other yogurts. In addition, thickness intensity of yogurts with WPI and TI were was highest on $d 1$. However, intensity of thickness in yogurts with WPI significantly increased on d 6 and 12. Physical measurements also indicated that WPIadded yogurts had the highest viscosity and the lowest syneresis (Table 3; Figure 1).

Chalkiness was another texture attribute evaluated in all yogurts. No significant effect of storage was determined on chalkiness $(P>0.05)$. However, there were significant differences among the yogurt samples $(P<$ 0.01 ). Yogurt fortified with $\mathrm{NaCn}$ was significantly chalkier (intensity of 2.4) than other yogurts. Chalkiness was also defined as a textural attribute for soy-fortified yogurts with an increasing content of soy protein (Drake et al., 2000). It was stated that enriching the milk base with protein and severe heating favor a granular texture (Sodini et al., 2004).

Flavor Attributes. Fermented flavor is a characteristic attribute for yogurt. Using different fortification materials may affect the fermentation of yogurt by starter cultures. After $1 \mathrm{~d}$ of storage, the control yogurt was characterized as having the highest intensity of fermented flavor (Table 5). There was no difference between the $\mathrm{NaCn}$-fortified yogurt and the control on d 12. In general, yogurts with WPI had lower fermented flavor scores than others over storage $(P<0.05)$. This might be due to the flavor-binding properties of whey proteins. Several proteins, specifically whey protein concentrates, carry undesirable flavors that limit their applications in food (Damodaran, 1996). Guichard and Langourieux (2000) stated that the presence of $\beta$-LG in aqueous solutions decreased the volatility of most hydrophobic interactions in the central cavity of the protein. Therefore, a significant decrease was observed in odor perception. 
Table 5. Fermented flavor changes in yogurts over $12 \mathrm{~d}$ of storage $^{1}$

\begin{tabular}{lllll}
\hline & \multicolumn{4}{c}{ Yogurt $^{2}$} \\
\cline { 2 - 5 } Time & Control & WPI & TI & NaCn \\
\hline Day 1 & $4.8^{\mathrm{Aa}}$ & $3.4^{\mathrm{Ab}}$ & $3.4^{\mathrm{Bb}}$ & $3.8^{\mathrm{Bb}}$ \\
Day 6 & $4.7^{\mathrm{Aa}}$ & $3.4^{\mathrm{Ab}}$ & $4.2^{\mathrm{Aa}}$ & $4.6^{\mathrm{Aa}}$ \\
Day 12 & $4.7^{\mathrm{Aa}}$ & $3.5^{\mathrm{Ac}}$ & $4.0^{\mathrm{Ab}}$ & $4.6^{\mathrm{Aa}}$ \\
\hline
\end{tabular}

${ }^{\mathrm{a}-\mathrm{c}}$ Means in the same row followed by different lowercase letters represent significant differences $(P<0.01)$.

${ }^{\mathrm{A}-\mathrm{C}}$ Means in the same column followed by different uppercase letters represent significant differences $(P<0.01)$.

${ }^{1}$ Attribute was scored on a 15 -point universal Spectrum intensity scale where $0=$ absence of the attribute and $15=$ extremely high intensity of the attribute (Meilgaard et al., 1999).

${ }^{2}$ Yogurts were fortified with skim milk powder (control), whey protein isolate (WPI), texture improver (TI), or sodium caseinate ( $\mathrm{NaCn}$ ).

Also, Hansen and Heins (1991) conducted a study to detect the effect of $\mathrm{NaCn}$ and WPC used in dairy deserts upon vanillin flavor perception in an aqueous system. They observed more flavor perception loss in the presence of WPC than NaCn. Their explanation was that more protein denaturation occurred in WPC production than in that of $\mathrm{NaCn}$. This denaturation could cleave disulfide linkages and permit amino acids that are normally buried within the protein to interact with the flavor compounds.

Table 6 shows the intensities of other flavor attributes. Treatment by time interactions were not detected for flavor attributes $(P>0.05)$. There was no difference among the samples for cooked flavor $(P>0.05)$; its intensity was between 1.7 and 1.9 for yogurts. Cooked flavor was identified for some dairy foods including liquid Cheddar whey (Karagul-Yuceer et al., 2003a), dried milk

Table 6. Flavor attributes of yogurts ${ }^{1}$

\begin{tabular}{llllll}
\hline & \multicolumn{5}{c}{ Yogurt $^{2}$} \\
\cline { 2 - 6 } Attribute & Control & WPI & TI & NaCn & $\begin{array}{l}\text { Treatment } \\
\times \text { time }^{3}\end{array}$ \\
\hline Creamy* & $1.4^{\mathrm{ab}}$ & $1.1^{\mathrm{b}}$ & $1.6^{\mathrm{a}}$ & $1.5^{\mathrm{a}}$ & No \\
Whey & $1.4^{\mathrm{b}}$ & $1.7^{\mathrm{a}}$ & $1.4^{\mathrm{b}}$ & $1.4^{\mathrm{b}}$ & No \\
Animal-like* & $0.8^{\mathrm{c}}$ & $0.7^{\mathrm{c}}$ & $1.8^{\mathrm{a}}$ & $1.1^{\mathrm{b}}$ & No \\
Cardboard* & $0.7^{\mathrm{b}}$ & $0.7^{\mathrm{b}}$ & $1.2^{\mathrm{a}}$ & $1.0^{\mathrm{a}}$ & No \\
Cereal & $0.7^{\mathrm{b}}$ & $0.9^{\mathrm{ab}}$ & $0.9^{\mathrm{ab}}$ & $1.0^{\mathrm{a}}$ & No \\
Astringent* & $2.1^{\mathrm{bc}}$ & $1.9^{\mathrm{c}}$ & $2.3^{\mathrm{ab}}$ & $2.5^{\mathrm{a}}$ & No \\
Aftertaste & $1.7^{\mathrm{b}}$ & $1.8^{\mathrm{ab}}$ & $2.2^{\mathrm{a}}$ & $2.1^{\mathrm{ab}}$ & No \\
\hline
\end{tabular}

${ }^{a, b, c}$ Means in the same row followed by different letters represent significant differences $(P<0.05)$; * Means in the same row followed by different letters represent significant differences $(P<0.01)$.

${ }^{1}$ Attributes were scored on a 15 -point universal Spectrum intensity scale where $0=$ absence of the attribute and $15=$ extremely high intensity of the attribute (Meilgaard et al., 1999). Values are the averages of $d 1$ to 12 .

${ }^{2}$ Yogurts were fortified with skim milk powder (control), whey protein isolate (WPI), texture improver (TI), or sodium caseinate (NaCn).

${ }^{3}$ Treatment by time interaction. powders (Drake et al., 2003), and rennet casein (Karagul-Yuceer et al., 2003b). Creamy flavor was also determined in all yogurt samples. Yogurt with WPI had lower creamy flavor than yogurts with $\mathrm{TI}$ and $\mathrm{NaCn}$. The other descriptive term developed by sensory panel was whey flavor. The highest intensity of whey flavor was also observed in WPI-fortified yogurt $(P<0.05)$.

Samples also differed from each other in intensity of some off-flavor attributes such as animal-like, cardboard, and cereal (Table 6). In the present study, SMP was reconstituted to prepare yogurt milk. Ideally, sensory properties of reconstituted milk should be similar to that of fresh skim milk. However, some flavors may develop in powders during production or storage. Dried dairy ingredients including milk powders, caseinates, and whey protein powders show flavor variability. Drake and coworkers (2003) determined frequently observed flavor attributes of SMP, caseinates, and WPC provided from the United States and other countries. The most common descriptors for SMP were cooked, sweet aromatic, cereal, animal/wet dog, potato-like, cardboard, sweet, salty, and astringent. However, the most intense flavors for caseinates and WPC were animal/wet dog, brothy, cardboard, and astringency. In the present study, animal-like flavor was the most intense in TI-fortified yogurt and the lowest in WPI-fortified and control yogurts $(P<0.01)$. Texture improver is a proprietary dairybased ingredient. Composition and process conditions of this ingredient may affect the sensory properties of it. Yogurts with $\mathrm{NaCn}$ also displayed distinct intensities of animal-like off-flavor; in fact, rehydrated $\mathrm{NaCn}$ was the reference for animal flavor in the current study. KaragulYuceer and coworkers (2003b) identified animal-like flavor as the key sensory descriptor for dried rennet caseins. They indicated that hexanoic acid, indole, guaia$\mathrm{col}$, and p-cresol were major contributors to this animallike flavor of rennet casein. In another study, both gas chromatography-olfactometry and sensory analysis were used to document that some milk powders had animal-like, cowy, or fecal flavors (Karagul-Yuceer et al., 2002).

Cardboard flavor was also detected in the samples by panelists (Table 6). The highest intensity was observed in $\mathrm{NaCn}$ - and TI-fortified yogurts. Cardboard or oxidized flavor was also determined in SMP, WPC with $80 \%$ protein, and caseinates (Karagul-Yuceer et al., 2002; Drake et al., 2003; Carunchia Whetstine et al., 2005). Light exposure or lipid oxidation may develop this flavor in food products. Generation of some aldehydes and ketones results in cardboard flavor (Grosch et al., 1994; Ho and Chen, 1994; Ulberth and Roubicek, 1995).

Cereal was the other flavor attribute observed in yogurt samples (Table 6). According to sensory evaluations, control and $\mathrm{NaCn}$-fortified yogurts were significantly dif- 
ferent from each other in terms of cereal flavor. Cerealtype flavor was also detected in sensory evaluations of SMP (Karagul-Yuceer et al., 2002; Drake et al., 2003). Karagul-Yuceer et al. (2002) hypothesized that cereal flavor in SMP was related to some heat-generated compounds including furaneol, methional, 2-acetyl-1-pyrroline, thiazoline, and thiazole. Aftertaste intensity of TI was significantly different from the control yogurt.

Astringency was also detected in all yogurts. Yogurts fortified with WPI and TI were not significantly different from the control in terms of astringency (Table 6). However, intensity of astringency was higher in yogurts with $\mathrm{NaCn}$ than control and WPI-added yogurts. Drake and coworkers (2003) investigated sensory properties of some dry ingredients including SMP, WPC, and caseinates. They showed that astringency intensities of SMP were higher than WPC and caseinates. Astringency is also a common sensory attribute related to high heat-treated or UHT milks (Harwalkar et al., 1989). Astringency was attributed to the interaction among whey proteins, calcium phosphate, and caseins in milk (Josephson et al., 1967). Harwalkar and coworkers (1993) linked astringency to the production of $\gamma$-caseins from $\beta$-casein by cleavage of the peptide bonds between 28 and 29, 105 and 106, and 107 and 108. In agreement with these results, in the present study, the intensity of astringency was higher in $\mathrm{NaCn}$-fortified yogurt than both the control and WPI-added yogurts.

There was no significant interaction between treatment and storage regarding sweetness attribute. In addition, there was a difference among yogurts in sweet taste $(P<0.05)$. Intensity of sweetness was similar for control, WPI-, and TI-added yogurts and ranged between 1.3 and 1.4. Yogurts with added $\mathrm{NaCn}$ had less sweetness (1.2) than the other yogurts. Sweetness is not normally expected to be at high intensities in plain yogurts. In the present study, the sweetness intensity of all yogurts decreased during storage $(P<0.01)$.

Sour taste was not different among the yogurts, but increased on $\mathrm{d} 12$ (3.4; $P<0.01$ ); $\mathrm{pH}$ drop was probably the reason for increasing the intensity of sour taste over storage. On $\mathrm{d} 1$ and 12, the ranges of $\mathrm{pH}$ measurements were 4.26 to 4.34 and 4.15 to 4.21 , respectively.

\section{Consumer Acceptance}

Sixty-six females and 77 males participated in this study. There was no significant effect of gender on the acceptability of yogurts. According to the consumer acceptance test, there was no difference among yogurts in terms of appearance and thickness attributes (Table 7). Based on flavor acceptance, WPI-fortified yogurt was the least preferred yogurt by consumers (Table 7). Trained panel evaluations also showed that WPI-added yogurt
Table 7. Consumer acceptance of yogurts ${ }^{1}$

\begin{tabular}{lllll}
\hline & \multicolumn{4}{c}{ Yogurt $^{2}$} \\
\cline { 2 - 5 } Attribute & Control & WPI & TI & NaCn \\
\hline Appearance & $5.7^{\mathrm{a}}$ & $5.8^{\mathrm{a}}$ & $6.1^{\mathrm{a}}$ & $5.7^{\mathrm{a}}$ \\
Thickness & $5.5^{\mathrm{a}}$ & $5.5^{\mathrm{a}}$ & $6.0^{\mathrm{a}}$ & $6.1^{\mathrm{a}}$ \\
Flavor & $5.8^{\mathrm{ab}}$ & $3.8^{\mathrm{c}}$ & $5.6^{\mathrm{b}}$ & $6.3^{\mathrm{a}}$ \\
Ranking test* & $2.3^{\mathrm{b}}$ & $1.5^{\mathrm{c}}$ & $2.8^{\mathrm{ab}}$ & $3.5^{\mathrm{a}}$ \\
\hline
\end{tabular}

${ }^{\mathrm{a}-\mathrm{c}}$ Means in the same row followed by different letters represent significant differences $(P<0.05)$; * Means in the same row followed by different letters represent significant differences $(P<0.01)$.

${ }^{1}$ Acceptance of yogurts was scored on a 9 -point hedonic scale anchored on the left with "dislike extremely" and on the right with "like extremely."

${ }^{2}$ Yogurts were fortified with skim milk powder (control), whey protein isolate (WPI), texture improver (TI), or sodium caseinate (NaCn).

had the lowest fermented flavor (Table 5). Based on the ranking test, preference of yogurts fortified with $\mathrm{NaCn}$ was higher than that of the control and WPI-fortified yogurts (Table 7). The reason for low acceptance of yogurts with WPI by Turkish consumers might be the low intensity of fermented flavor. In addition, yogurts with $\mathrm{TI}$ and $\mathrm{NaCn}$ had more intense animal-like flavor than others (Table 6). Control and WPI-fortified yogurts had the same intensities of animal-like flavor (Table 6). However, flavor acceptances of yogurts with $\mathrm{TI}$ and $\mathrm{NaCn}$ were not significantly different than control yogurt (Table 7). For this reason, specifically fermented flavor attribute is very crucial to Turkish consumer for acceptance of yogurt. The low level of fermented flavor in yogurts with WPI decreased the acceptability of these yogurts. In summary, the consumer results are cultural in nature. The same results would not necessarily be observed among consumers in other countries.

\section{CONCLUSIONS}

The effects of WPI, NaCn, and TI on some physical and sensory properties of nonfat yogurt were investigated. Fortification with WPI increased the viscosity and decreased the syneresis of yogurts. However, sensory properties of nonfat yogurt were negatively affected by using WPI. Yogurts enriched with either NaCn or TI displayed higher viscosity and less syneresis than control yogurt. In general, $\mathrm{NaCn}$ and TI yogurts had better sensory properties than control yogurts. Consumers preferred yogurts fortified with $\mathrm{NaCn}$. Using $\mathrm{NaCn}$ or TI may develop better physical and sensory properties in yogurts. Further studies with these types of dry dairy ingredients at different concentrations may help to improve some physical and sensory properties of nonfat yogurt. 


\section{ACKNOWLEDGMENTS}

This research was funded by TUBITAK (The Scientific and Technological Research Council of Turkey) and Scientific Research Fund of Canakkale Onsekiz Mart University. The authors gratefully express their gratitude to Fonterra (Germany) and Pinar Sut A.S. (Turkey) for their generous donation of dry ingredients. The authors also thank the panel members for their participation and input during panel training and product evaluation.

\section{REFERENCES}

Abu-Jdayil, B., and H. Mohameed. 2002. Experimental and modelling studies of the flow properties of concentrated yogurt as affected by the storage time. J. Food Eng. 52:359-365.

Akbay, C. 2006. Animal products consumption patterns of rural households in Turkey. Livestock Research For Rural Developments 18(1). http://www.cipav.org.co/lrrd//rrd18/1/akba18013.htm Accessed Feb. 2, 2006.

Amatayakul, T., F. Sherkat, and N. P. Shah. 2006. Physical characteristics of set yogurt made with altered casein to whey protein ratios and EPS-producing starter cultures at 9 and $14 \%$ total solids. Food Hydrocoll. 20:314-324.

Carunchia-Whetstine, M. E., A. E. Croissant, and M. A. Drake. 2005. Characterization of dried whey protein concentrate and isolate flavor. J. Dairy Sci. 88:3826-3839.

Damodaran, S. 1996. Amino acids, Peptides, and Proteins. Pages 385389 in Food Chemistry. O. R. Fennema, ed. Marcel Dekker, Inc, New York, NY.

Drake, M. A., X. O. Chen, S. Tamarapu, and B. Leenanon. 2000. Soy protein fortification affects sensory, chemical and microbiological properties of dairy yogurts. J. Food Sci. 65:1244-1247.

Drake, M. A., Y. Karagul-Yuceer, K. R. Cadwallader, G. V. Civille, and P. S. Tong. 2003. Determination of the sensory attributes of dried milk powders and dairy ingredients. J. Sens. Stud. 18:199-216.

Ennis, M. P., and D. M. Mulvihill. 2000. Milk proteins. Pages 185213 in Handbook of Hydrocolloids. G. O. Phillips and P. A. Williams, ed. CRC Press LLC, Washington, DC.

Fox, P. F. 2001. Milk proteins as food ingredients. Int. J. Dairy Technol. 54:41-55.

Gonzalez-Martinez, C., M. Becerra, M. Chafer, A. Albors, J. M. Carot, and A. Chiralt. 2002. Influence of substituting milk powder for whey powder on yoghurt quality. Trends Food Sci. Technol. 13:334-340.

Grosch, W., C. Milo, and S. Widder. 1994. Identification and quantification of odorants causing off-flavors. Pages 409-415 in Trends in Flavor Research. H. Maarse and D. G. Van der Heij, ed. Elsevier Science, London, UK.

Guichard, E., and S. Langourieux. 2000. Interactions between $\beta$-lactoglobulin and flavor compounds. Food Chem. 71:301-308.

Guzman-Gonzalez, M., F. Morais, and L. Amigo. 2000. Influence of skimmed milk concentrate replacement by dairy products in a lowfat set-type yogurt model system. Use of caseinates, co-precipitate and blended dairy powders. J. Sci. Food Agric. 80:433-438.

Ha, E., and M. B. Zemel. 2003. Functional properties of whey, whey components, and essential aminoacids: Mechanisms underlying health benefits for active people. J. Nutr. Biochem. 14:251-258.

Hansen, A. P., and J. J. Heinis. 1991. Decrease of vanillin flavor perception in the presence of casein and whey proteins. J. Dairy Sci. 74:2936-2940.
Haque, Z. U., and T. Ji. 2003. Cheddar whey processing and source: II. Effect on non-fat ice cream and yogurt. Int. J. Food Sci. Technol. 38:463-473.

Harwalkar, V. R., B. Boutin-Muma, H. Cholette, R. C. McKellar, and D. B. Emmons. 1989. Isolation and partial purification of astringent compounds from ultrahigh-temperature sterilized milk. J. Dairy Res. 56:367-373.

Harwalkar, V. R., H. Cholette, R. C. McKellar, and D. B. Emmons. 1993. Relation between proteolysis and astringent off-flavor in milk. J. Dairy Sci. 76:2521-2527.

Hekmat, S., and D. J. McMahon. 1997. Manufacture and quality of iron-fortified yogurt. J. Dairy Sci. 80:3114-3122.

Ho, C. T., and Q. Chen. 1994. Lipids in food flavors. Pages $2-14$ in Lipids in Food Flavors. C. T. Ho and T. G. Hartman, ed. ACS Symposium Series 558; American Chemical Society: Washington, DC.

Josephson, R. V., E. L. Thomas, C. V. Morr, and S. T. Coulter. 1967. Relation of heat-induced changes in protein-salt constituents and astringency in milk system. J. Dairy Sci. 50:1376-1383.

Karagul-Yuceer, Y., K. R. Cadwallader, and M. A. Drake. 2002. Volatile flavor components of stored nonfat dry milk. J. Agric. Food Chem. 50:305-312.

Karagul-Yuceer, Y., M. A. Drake, and K. R. Cadwallader. 2003a. Aroma active components of liquid Cheddar whey. J. Food Sci. 68:1215-1219.

Karagul-Yuceer, Y., K. L. Vlahovich, M. A. Drake, and K. R. Cadwallader. 2003b. Characteristic aroma components of rennet casein. J. Agric. Food Chem. 51:6797-6801.

Lucey, J. A. 2002. Formation and physical properties of milk protein gels. J. Dairy Sci. 85:281-294.

Lucey, J. A., and H. Singh. 1998. Formation and physical properties of acid milk gels: A review. Food Res. Int. 30,7:529-542.

McKinley, M. C. 2005. The nutrition and health benefits of yoghurt. Int. J. Dairy Technol. 58:1-12.

Meilgaard, M., G. V. Civille, and B. T. Carr. 1999. The Spectrum descriptive analysis method. Pages 173-229 in Sensory Evaluation Techniques. 3rd ed. CRC Press, Inc., Boca Raton, FL.

Mistry, V. V., and H. N. Hassan. 1992. Manufacture of nonfat yogurt from a high milk protein powder. J. Dairy Sci. 75:947-957.

Modler, H. W., M. E. Larmond, C. S. Lin, D. Froehlich, and D. B. Emmons. 1983. Physical and sensory properties of yogurt stabilized with milk proteins. J. Dairy Sci. 66:422-429.

Puvanenthiran, A., R. P. W. Williams, and M. A. Augustin. 2002. Structure and visco-elastic properties of set yogurt with altered casein to whey protein ratios. Int. Dairy J. 12:383-391.

Remeuf, F., S. Mohammed, I. Sodini, and J. P. Tissier. 2003. Preliminary observations on the effects of milk fortification and heating on microstructure and physical properties of stirred yogurt. Int. Dairy J. 13:773-782.

Sheskin, D. J. 2000. Pages 669-684 in Parametric and Nonparametric Statistical Procedures. Chapman and Hall/CRC, New York, NY.

Sodini, I., F. Remeuf, S. Haddad, and G. Corrieu. 2004. The relative effect of milk base starter, and process on yogurt texture: A review. Crit. Rev. Food Sci. Nutr. 44:113-137.

Tamime, A. Y., E. Barrantes, and A. M. Sword. 1996. The effects of starch-based fat substitutes on the microstructure of set-style yogurt made from reconstituted skimmed milk powder. J. Soc. Dairy Technol. 49:1-10.

Tamime, A. Y., and R. K. Robinson. 2000. Yogurt Science and Technology. CRC Press, Washington, DC.

Ulberth, F., and D. Roubicek. 1995. Monitoring of oxidative deterioration of milk powder by headspace gas chromatography. Int. Dairy J. 5:523-531.

Warner, E. A., A. D. Kanekanian, and A. T. Andrews. 2001. Bioactivity of milk proteins: 1 . Anticariogenicity of whey proteins. Int. J. Dairy Technol. 54:151-153. 